\title{
Редкометалльные пегматиты северо-восточной части Кольского пегматитового пояса: геология и геохимия (Кольский полуостров)
}

\author{
Морозова Л.Н. \\ Геологический институт КНЦ РАН, Anamumbl, morozova@geoksc.apatity.ru
}

Аннотация. В статье приводятся данные по геохимии пегматитов района Солдат-Мыльк северовосточной части Кольского пегматитового пояса. Показано, что сподуменовые и полевошпатовые пегматиты имеют черты типичные для пегматитов редкометалльного типа: повышенные содержания $\mathrm{Li}, \mathrm{Be}, \mathrm{Ta}, \mathrm{Nb}, \mathrm{Cs}$, $\mathrm{Rb}$ P, B, пониженные содержания $\mathrm{Sr}, \mathrm{Ba}, \mathrm{Zr}$ и REE, низкие величины отношений Zr/Hf, Ba/Rb, Sr/Rb. Полученные данные указывают на перспективность пегматитов в отношении редкометалльного оруденения.

Ключевые слова: редкометалльные пегматиты, Балтийский щит, зона Колмозеро-Воронья, литиевая минерализация.

\section{Rare-metal pegmatites of the north-eastern part of Kola pegmatite belt: geology and geochemistry (Kola Peninsula)}

\author{
Morozova L.N. \\ Geological institute KSC RAS, Apatity, morozova@geoksc.apatity.ru
}

\begin{abstract}
The article presents data on the geochemistry of pegmatites in the Soldier-Mylk region of the northeastern part of the Kola pegmatite belt. Spodumene and feldspar pegmatites were shown to have features typical of rare-metal pegmatites: elevated $\mathrm{Li}, \mathrm{Be}, \mathrm{Ta}, \mathrm{Nb}, \mathrm{Cs}, \mathrm{Rb} \mathrm{P}, \mathrm{B}$, low $\mathrm{Sr}, \mathrm{Ba}, \mathrm{Zr}$ and REE, low ratios $\mathrm{Zr} / \mathrm{Hf}, \mathrm{Ba} / \mathrm{Rb}, \mathrm{Sr} / \mathrm{Rb}$. The data obtained indicate the promise of pegmatite in relation to rare metal mineralization.
\end{abstract}

Key words: rare metal pegmatites, Baltic Shield, Kolmozero-Voronya zone, lithium mineralization.

\section{Введение}

Во всем мире возрастает интерес к месторождениям и рудопроявлениям редкометалльных пегматитов, как основных источников лития. Крупные промышленные месторождения редкометалльных пегматитов расположены в США, Конго, Китае, Австралии, России, Бразилии, Канаде, Португалии и Зимбабве. Внимание к редкометальным пегматитам во всем мире обусловлено тем, что запасы лития в месторождениях редкометалльных пегматитов могут достигать первых миллионов тонн.

Литий в России относится к широко востребованным металлам стратегического назначения. Сырье для его производства поступает из-за рубежа. В условиях возрастающего в мировом масштабе спроса на литий и выбранного правительством РФ курса на импортозамещение актуальной является проблема обеспечения страны литиевым сырьем за счет разработок отечественных рудопроявлений и месторождений редкометалльных пегматитов, прежде всего, на Кольском полуострове.

Пегматиты, как правило, не встречаются в виде одиночных тел. В пределах пегматитового поля может быть сосредоточено от десятков до сотен пегматитовых жил. Из пегматитовых тел практический интерес могут представлять весьма ограниченное их количество. Поэтому существует проблема выявления редкометалльных пегматитов на стадии проведения геологоразведочных и поисково-оценочных работ. Наиболее объективными, воспроизводимыми и высокоинформативными для этих целей являются геохимические показатели.

Кольский пегматитовый пояс протягивается с северо-запада (р. Воронья) на северо-восток (оз. Кальмозеро) на 130 км и включает крупные месторождения редкометалльных пегматитов: Васин-Мыльк, Олений хребет, Охмыльк, Полмостундровское, Колмозерское (Пожиленко и др., 2002; Гордиенко, 1970, Морозова, 2018). Кроме крупных месторождений в пределах пегматитового пояса отмечаются многочисленные жилы пегматитов, которые также могут представлять интерес в отношении редкометалльного оруденения. Примером таких пегматитов являются пегматиты района Солдат-Мыльк, расположенные к северо-западу от Колмозерского литиевого месторождения. 
Выполненные исследования направлены на доизучение вещественного состава пегматитов Солдат-Мылька и сравнение их редкоэлементного состава с составом хорошо изученных редкометалльных пегматитов Колмозерского пегматитового поля.

\section{Строение и состав пегматитов жил}

В районе Солдат-Мыльк отмечаются выходы жил сподуменовых и полевошпатовых пегматитов. Жила сподуменовых пегматитов имеет протяженность около 400 м и мощность от 45 до 85 м и секущие контакты с гранатовыми амфиболитами зеленокаменного комплекса КолмозероВоронья. В строении жилы были выделены следующие зоны. Зона-І мелкозернистого кварцполевошпатового агрегата мощностью от 3 до 5 см, прослеженная фрагментарно. Зона-II среднезернистого кварц-мусковит-полевошпатового пегматита (10-20 см) с розовато-бурым спессартином, синевато-зеленым апатитом и мелкозернистым черным турмалином. К зоне-III крупно- гигантозернистого кварц-сподумен-полевошпатового пегматита, слагающего основной объем жилы, приурочены рудные минералы - сподумен, берилл и минералы группы колумбита. Кристаллы зеленоватого сподумена достигают размеров $20 \times 3.5 \mathrm{~cm}$, а зеленовато-желтого пластинчатого мусковита $-3 \times 2 \mathrm{~cm}$. На участках развития блокового кварца и микроклина отмечаются кристаллы шерла размером $5 \times 2 \mathrm{~cm}$. Центральная зона-IV сложена кварцевым ядром.

Жилы полевошпатовых пегматиты достаточно широко развиты в породах зеленокаменного комплекса Колмозеро-Воронья. Протяженность жил варьирует от 50 до 150 м при видимой мощности от 10 до 20 м. Внутреннее строение жил слабо зональное и характеризуется наличием хорошо выраженной внутренней зоны, сложенной кварц-полевошпатовым пегматитом неравномернозернистой структуры. К этой зоне приурочены участки, сложенные блоковым микроклином и кварцем и мелкозернистым кварц-плагиоклазовым агрегатом с мелкочешуйчатым желтовато-зеленым мусковитом, черным турмалином и сине-зеленым апатитом. Наряду с мелкозернистым турмалином в пегматитах отмечаются призматические кристаллы шерла размером $9 \times 2$ см.

\section{Редкоэлементный состав пегматитов}

Сподуменовые пегматиты Солдат-Мылька характеризуются относительно повышенными содержаниями $\mathrm{SiO}_{2}$ и $\mathrm{Al}_{2} \mathrm{O}_{3}$ и пониженными, по сравнению с кларком гранита, содержаниями $\mathrm{TiO}_{2}, \mathrm{Fe}_{2} \mathrm{O}_{3}, \mathrm{FeO}, \mathrm{MnO}, \mathrm{MgO}, \mathrm{CaO}$. Содержание $\mathrm{P}_{2} \mathrm{O}_{5}(0.35$ мас. \%) и В (190 г/т) превышает содержание этих элементов в кларке гранита (0.16 мас. \% и 15 г/т, соответственно; Виноградов, 1962), а F (0.02 мас. \%) - более низкое (0.08 мас. \%; Виноградов, 1962). Такой состав флюсующих компонентов обеспечивает присутствие в породах апатита и турмалина. Изученные пегматиты отличаются от альбит-сподуменовых пегматитов Колмозерского литиевого месторождения (7 г/т и 0.15 мас. \%, соответственно; Морозова, 2018) повышенными содержаниями бора и фосфора

Содержание лития, ниобия, тантала и бериллия в сподуменовых $(673,58,45$ и 103 г/т) и полевошпатовых $(45,35,38$ и 112 г/т) пегматитах Солдат-Мылька, как и в пегматитах Колмозерского пегматитового поля, превышает содержание этих рудных элементов в кларке гранита.

Сподуменовые пегматиты Солдат-Мылька обеднены редкоземельными элементами $\left(\sum \mathrm{REE}=1.87\right.$ г/T) и характеризуются слабо фракционированным спектром распределения лантаноидов $\left((\mathrm{La} / \mathrm{Yb})_{\mathrm{N}}=1.47-2.31\right)$ с ярко выраженной отрицательной Еu-аномалией $\left(\mathrm{Eu} / \mathrm{Eu}^{*}=0.10-0.14\right)$ (рис. 1 a). Наличие отрицательной Еu-аномалии при низких содержаниях $\mathrm{Sr}$ свидетельствует о фракционировании плагиоклаза при обогащении расплава несовместимыми компонентами. На графиках распределения редкоземельных элементов отмечаются положительные перегибы на участке Gd-Tb-Dy. Такая конфигурация графиков обусловлена относительно повышенными содержаниями средних лантаноидов по сравнению с тяжелыми. Графики распределения редкоземельных элементов для изученных полевошпатовых пегматитов также характеризуются слабо дифференцированным спектром $\left((\mathrm{La} / \mathrm{Yb})_{\mathrm{N}}=4.04-2.82\right)$ и ярко выраженной отрицательной $\mathrm{Eu}-$ аномалией $\left(\mathrm{Eu} / \mathrm{Eu}^{*}=0.09-0.06\right)$ (рис. 1 б).

Тренды распределения редкоземельных элементов сподуменовых и полевошпатовых пегматитов Солдат-Мылька показывают отличие от графиков распределения лантаноидов альбит- 

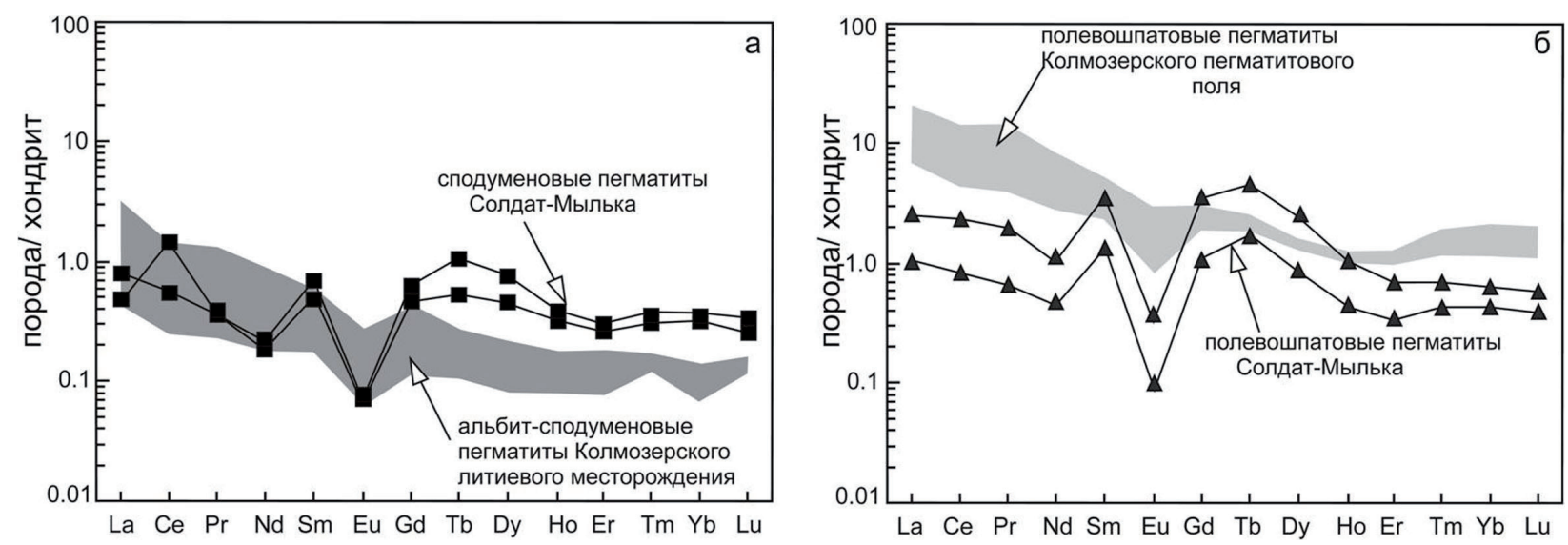

Рис. 1. Распределение редкоземельных элементов в сподуменовых (а) и полевошпатовых (б) пегматитов района Солдат-Мыльк. Нормировано на хондрит по (Boynton, 1984).

Fig. 1 Distribution of rare-earth elements in spodumene (a) and feldspar (b) pegmatites of the Soldat-Mylk region. Chordrite-normalized after (Boynton, 1984).

сподуменовых и полевошпатовых пегматитов Колмозерского пегматитового поля (рис. 1 a, б). По сравнению с альбит-сподуменовыми пегматитами Колмозерского литиевого месторождения сподуменовые пегматиты Солдат-Мылька имеют менее дифференцированные спектры распределения $\mathrm{REE}$, повышенные содержания средних (Gd, Tb, Dy) и тяжелых лантаноидов, более ярко выраженную отрицательную европиевую аномалию. Полевошпатовые пегматиты Солдат-Мылька по сравнению с полевошпатовыми пегматитами Колмозерского пегматитового поля имеют менее дифференцированный спектр распределения REE, обеднены легкими и тяжелыми лантаноидами и имеют более ярко выраженную отрицательную европиевую аномалию.

Содержание высокозарядных элементов с высокой валентностью (HFS) - REE, Th, Zr, Y, и крупноионных литофильных элементов (LIL) - Sr и Ва, в сподуменовых и полевошпатовых пегматитах Солдат-Мылька, как и в редкометалльных пегматитах Колмозерского пегматитового поля, ниже, чем в кларке гранита (рис. 2). В то же время содержание бария и стронция в полевошпатовых пегматитах (446 и 98 г/т, соответственно, Морозова, 2018) Колмозерского пегматитового поля в несколько раз превышает содержание этих элементов в полевошпатовых (46 и 35 г/т, соответственно) пегматитах Солдат-Мылька.

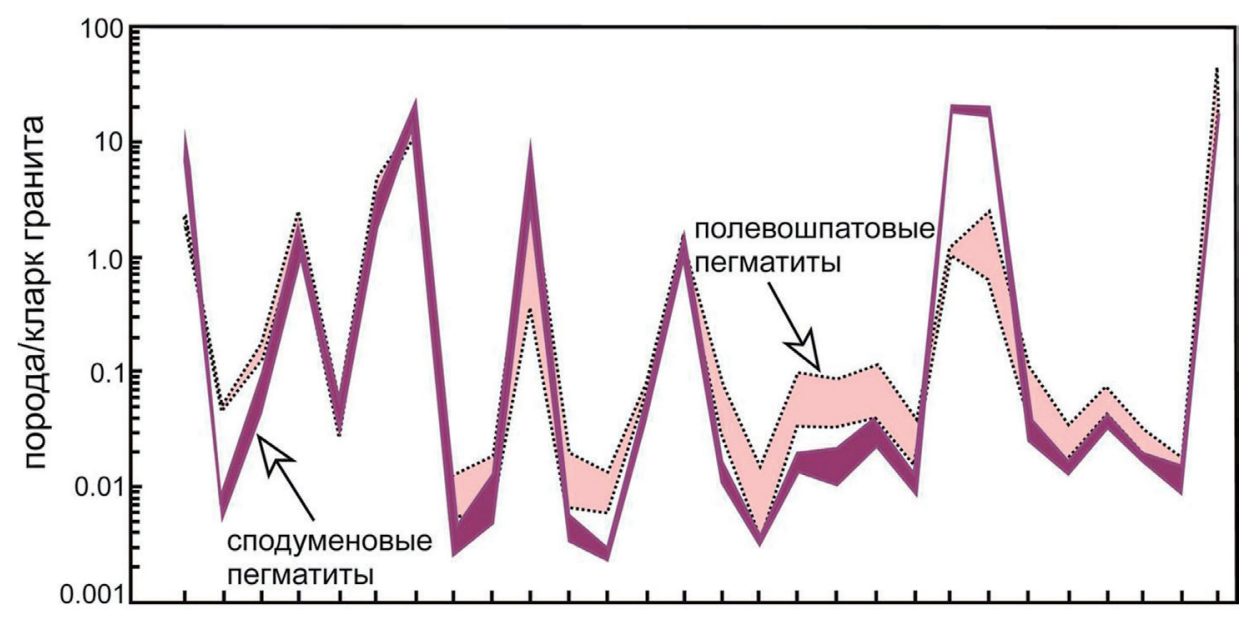

$\mathrm{Rb} \mathrm{Ba} \mathrm{Sr}$ U Th Nb Ta La Ce Cs PrNd Zr Hf Sm Eu Gd Tb Dy Ho Li Be Y ErTm Yb Lu B

Рис. 2. Распределение редких элементов в редкометалльных сподуменовых и полевошпатовых пегматитов района Солдат-Мыльк. Нормировано на кларк гранита по (Виноградов, 1962).

Fig. 2. Distribution of rare elements in rare-metal spodume and feldspar pegmatites of the Soldat-Mylk region. Chordrite-normalized after (Vinogradov, 1962). 
Величины отношений $\mathrm{Mg} / \mathrm{Li}, \mathrm{Zr} / \mathrm{Hf}, \mathrm{Ba} / \mathrm{Rb}, \mathrm{Sr} / \mathrm{Rb}$ в изученных пегматитах низкие и показывают закономерное снижение от полевошпатовых $(9.74,10.9,0.08,0.11$, соответственно) к сподуменовым $(0.43,8.3,0.01,0.02$, соответственно) пегматитам. Для всех типов пегматитов устанавливается значимая положительная корреляционная связь между $\mathrm{Sr} / \mathrm{Rb}-\mathrm{Sr}(\mathrm{r}=0.92)$ и $\mathrm{Ba} / \mathrm{Rb}-\mathrm{Ba}(\mathrm{r}=0.99)$.

Мультиэлементные спектры несовместимых элементов, нормированные к кларку гранита, рассматриваемых типов пегматитов имеют сходную конфигурацию и показывают положительные аномалии Cs, Rb, U, Nb-Ta, Cs, Hf, Li, Be, В и отрицательные аномалии Ba-Sr и Th (рис. 2).

\section{Обсуждение результатов}

Гранитные рудогенерирующие расплавы, которые являются источниками месторождений и рудопроявлений редкометалльных пегматитов, возникают на различных этапах геологической истории развития Земли. Потенциальная рудоносность этих расплавов обусловлена различными факторами, существенными из которых являются состав источника, флюидный и термодинамический режимы. Рудная специализация пегматитовых комплексов находит свое отражение в их приуроченности к одной геологической структуре, одновременности или сближенности во времени образования, сходстве фациально-глубинных условий формирования, закономерном расположении относительно рудогенерирующих массивов гранитов, в минералогических и петрохимических признаках родства и т.д.

Многочисленные исследованиями показали, что типичной чертой вещественного состава редкометалльных пегматитов является высокое содержание в них гранитофильных элементов $\mathrm{Li}, \mathrm{Be}, \mathrm{Ta}, \mathrm{Nb}, \mathrm{Cs}, \mathrm{Rb}$, флюсующих компонентов - B, Cl, F, P, а также Si и Al на фоне низких содержаний $\mathrm{Ti}, \mathrm{Mg}, \mathrm{Fe}, \mathrm{Mn} \mathrm{Ca}$, крупноионных литофильных элементов ( $\mathrm{Sr}, \mathrm{Ba}$ ) и высокозарядных элементов с высокой валентностью (Y, Zr, REE). В ряду от менее дифференцированных к более дифференцированным пегматитам, принадлежащим единой формации, отмечается снижение величины отношений $\mathrm{Mg} / \mathrm{Li} ; \mathrm{Zr} / \mathrm{Hf}, \mathrm{Ba} / \mathrm{Rb}, \mathrm{Sr} / \mathrm{Rb}$ и накопление в поздних дифференциатах $\mathrm{Li}, \mathrm{Rb}, \mathrm{Cs}, \mathrm{Be}$, $\mathrm{Nb}, \mathrm{Ta}, \mathrm{F}, \mathrm{B}$ и уменьшение содержания Sr, Ba, Y, Zr, REE (Зарайский и др., 2009; Černý; 1991, 1992; Морозова, 2018).

Установлено, что рассмотренные сподуменовые и полевошпатовые пегматиты СолдатМылька по вещественному составу имеют сходные геохимические черты с редкометальными пегматитами Колмозерского пегматитового поля: повышенные содержания $\mathrm{Li}, \mathrm{Be}, \mathrm{Ta}, \mathrm{Nb}, \mathrm{Rb}$, низкие содержания $\mathrm{Sr}, \mathrm{Ba}, \mathrm{Y}, \mathrm{Zr}$ и REE. Это позволяет рассматривать сподуменовые и полевошпатовые пегматиты Солдат-Мылька перспективными в отношении редкометалльного оруденения.

В то же время между редкометалльными пегматитами Солдат-Мылька и Колмозерского пегматитового поля выявлены различия по содержанию бора, фосфора, стронция, бария, легких и тяжелых лантаноидов, степени дифференциации редкоземельных элементов и величине европиевой аномалии. Эти отличия могут быть обусловлены различными факторами: составом гранитного источника и (или) степенью дифференциации гранитного расплава.

\section{Выводы}

1. Сподуменовые и полевошпатовые пегматиты района Солдат-Мыльк имеют четры типичные для пегматитов редкометалльного типа: повышенные содержания $\mathrm{Li}, \mathrm{Be}, \mathrm{Ta}, \mathrm{Nb}, \mathrm{Cs}, \mathrm{Rb} \mathrm{P}, \mathrm{B}$, пониженные содержания $\mathrm{Sr}, \mathrm{Ba}, \mathrm{Zr}$ и REE, низкие величины отношений $\mathrm{Zr} / \mathrm{Hf}, \mathrm{Ba} / \mathrm{Rb}, \mathrm{Sr} / \mathrm{Rb}, \mathrm{K} / \mathrm{Rb}$.

2. Сподуменовые пегматиты Солдат-Мылька отличаются от альбит-сподуменовых пегматитов Колмозерского литиевого месторождения повышенными содержаниями бора, фосфора, средних (Gd, Tb, Dy) и тяжелых лантаноидов, менее дифференцированным спектром распределения лантаноидов $\left((\mathrm{La} / \mathrm{Yb})_{\mathrm{N}}\right)$ и более ярко выраженной отрицательной европиевой аномалией $(\mathrm{Eu} / \mathrm{Eu} *)$.

3. Полевошпатовые пегматиты Солдат-Мылька по сравнению с полевошпатовыми пегматитами Колмозерского пегматитового поля обогащены бором, обеднены барием, стронцием, легкими и тяжелыми лантаноидами, имеют менее дифференцированный спектр распределения REE $\left((\mathrm{La} / \mathrm{Yb})_{\mathrm{N}}\right)$ и более ярко выраженную отрицательную европиевую аномалию (Eu/Eu*). 
4. Повышенные содержания $\mathrm{Li}, \mathrm{Be}, \mathrm{Nb}$ и Та в пробах из сподуменовых и полевошпатовых пегматитов Солдат-Мылька позволяют рассматривать изученные пегматиты в качестве перспективных на редкометалльное оруденение.

Автор выражает благодарность Е.Л. Кунаккузину и Е.С. Борисенко за участие в полевых работах.

Работа выполнена в рамках темы НИР № 0220-2019-0053.

\section{Литература}

1. Виноградов А.П. Средние содержания химических элементов в главных типах изверженных горных пород земной коры // Геохимия. 1962. № 7. С. 555-565.

2. Гордиенко В.В. Минералогия, геохимия и генезис сподуменовых пегматитов. Л. Изд-во: Недра. 1970. 240 с.

3. Зарайский Г.П., Аксюк А.М., Девятова В.Н. Цирконий-гафниевый индикатор фракционирования редкометалльных гранитов // Петрология. 2009. № 1. С. 28-50.

4. Морозова Л.Н. Колмозерское литиевое месторождение редкометалльных пегматитов: новые данные по редкоэлементному составу (Кольский полуостров) // Литосфера. 2018. № 18(1). С. 82-98.

5. Пожиленко В.И. Гавриленко Б.В., Жиров Д.В., Жабин С.В. Геология рудных районов Мурманской области. Апатиты: Изд-во КНЦ РАН. 2002. 359 с.

6. Boynton W.V. Cosmochemistry of the rare earth elements: Meteorite studies // Rare earth element geochemistry / ed.: P. Henderson. Amsterdam. Elsevier. 1984. P. 63-114.

7. Černý P. Rare-element granitic pegmatites. Part 1: Anatomy and internal evolution of pegmatite deposits // Geoscience Canada. 1991. V. 18 (2). P. 49-67.

8. Cerný P. Geochemical and petrogenetic features of mineralization in rare-element granitic pegmatite in the light of current research // Applied Geochemistry. 1992. V. 7. P. 393-416. 